\title{
A COMPARATIVE MICROLEAKAGE ANALYSIS OF ION-RELEASING SELF-ADHERABLE MATERIALS
}

\author{
Duygu Recen' 1 D, Başak Yazkan² (D) \\ ${ }^{1}$ Faculty of Dentistry, İmir Democracy University, Turkey \\ ${ }^{2}$ Faculty of Dentistry, Pamukkale University, Turkey
}

\begin{abstract}
INTRODUCTION: Despite the advancements in restorative materials, there are certain drawbacks, including microleakage resulting from insufficient wall adaptation. An effective seal at the tooth/restoration interface is crucial.

ОвJECTIVEs: The aim of the study was to investigate microleakage of different self-adhesive restorative materials. MATERIAL AND METHODs: Class- $\mathrm{V}$ cavities were prepared and divided into seven experimental groups with regards to applied material and pre-treatment procedures $(n=12)$. Cavities were restored with self-adhesive materials, such as hybrid glass ionomer (HGI) without pre-treatment (PT), HGI with PT, glass carbomer (GCP) without PT, GCP with PT, alkasite without adhesive resin (AR), alkasite with AR, nanohybrid composite resin with AR, and compared in terms of microleakage. Data were analyzed using Kolmogorov-Smirnov, Kruskal-Wallis, and Mann-Whitney U tests, with SPSS.

RESULTS: Significant difference in microleakage was found among enamel and dentin $(p<0.05)$. Leakage values from enamel were obtained as follows: alkasite with $\mathrm{AR}$ = nanohybrid composite resin with $\mathrm{AR}<$ alkasite without $\mathrm{AR}<\mathrm{HGI}$ with $\mathrm{PT}<\mathrm{HGI}$ without $\mathrm{PT}=\mathrm{GCP}$ with $\mathrm{PT}<\mathrm{GCP}$ without $\mathrm{PT}$, while leakage values obtained from dentin included alkasite with $\mathrm{AR}=$ nanohybrid composite resin with $\mathrm{AR}=$ alkasite without $\mathrm{AR}=\mathrm{HGI}$ with $\mathrm{PT}<\mathrm{HGI}$ without $\mathrm{PT}=\mathrm{GCP}$ with $\mathrm{PT}<\mathrm{GCP}$ without $\mathrm{PT}$.

ConcLusions: Microleakage properties are material-dependent and may vary due to ingredients. Alkasite with AR could be an alternative to nanohybrid composite due to better sealing ability of both enamel and dentin, while alkasite without AR and HGI with PT are the preferred materials for dentin. GCP without PT showed the highest microleakage.
\end{abstract}

KEY WORDS: alkasite, hybrid glass ionomer, glass carbomer, nanohybrid composite resin, microleakage.

J Stoma 2021; 74, 4: 203-210

DOI: https://doi.org/10.5114/jos.2021.111617

\section{INTRODUCTION}

Over the past years, demands have been raising for a restorative material with better physical properties, good esthetics, and long-lasting performance, with acceptable cost. Despite the developments in restorative materials, there are certain drawbacks, including microleakage, marginal staining, secondary caries, post-op sensitivity, and pulpal and periapical pathology progress due to insufficient wall adaptation. Therefore, at this point, an effective seal at the tooth/restoration interface is crucial. Nowadays, various direct restorative material options are available from amalgam to tooth-colored esthetic restoratives, with each having its' own advantages and disadvantages. Despite a great change in directly placed dental restorative materials, simple and basic choices are still in demand [1-3].

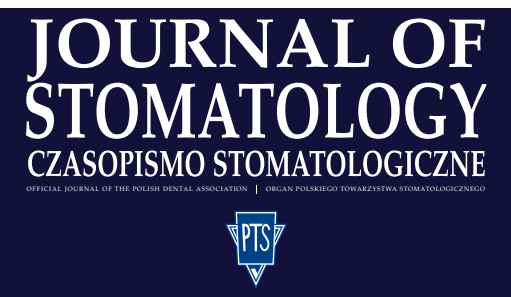

AdDRess For CORRESPONDENCE: Duygu Recen, Faculty of Dentistry, İzmir Democracy University, Street 13, 35140, Konak, İzmir, Turkey, e-mail: recenduygu@hotmail.com

ReCEIVED: 12.04.2021 • ACCEPTED: 31.05.2021 • PUBlished: 30.11.2021 
Self-adhesive, tooth-colored restorative materials are user-friendly options because of shorter application times, simplicity, and less sensitive technique, especially in the presence of moisture in the cavity [4]. They provide a chemical bond to dental hard tissues by self-etching and/or self-adhesive monomers [5].

For a restorative material, bioactivity it also important, which defines antibacterial effect of a material to inhibit or treat infection [6]. Glass ionomer cements (GICs) have been used since the 70 s of the last century as base materials, luting agents, and restorative materials in various areas of dentistry. GICs provide chemical bond with hard dental tissues by chelation of carboxyl group of acid polymeric chains and calcium ions $\left(\mathrm{Ca}^{2+}\right)$ in the apatite of enamel and dentine [7]. Due to bioactive characteristics of fluoride releasing GICs, hard tissue remineralization and protection against secondary caries can be achieved in contrast to materials, such as composite resin, amalgam, and dental ceramic that are bioinert [8].

GICs are susceptible to moist in the first $10 \mathrm{~min}$ following curing. To overcome this major clinical problem, surface coatings, including cocoa butter and petroleum jelly, waterproof varnishes, methyl methacrylates, amides, and light-curing resins are recommended [9]. Many modifications have been performed to conventional GICs to discard disadvantages of brittleness, which may lead to fracture, poor wear resistance, inadequate surface properties, and moisture sensitivity [6].

Lately, in order to prevent moisture sensitivity, and increase hardness and resisting of material under occlusal forces, a powder/ liquid ratio, particle size, and distribution were changed, and hybrid glass ionomer (HGI) materials were introduced [10]. EQUIA Forte Fil (GC; Tokyo, Japan) is commercially available HGI, with better physical and mechanical properties incorporating ultrafine, highly reactive glass particles spread in higher molecular weight polyacrylic acid. It is used together with a nano-filled coating material (EQUIA Forte Coat, GC; Tokyo, Japan), which optimize marginal seal and wear resistance, and is indicated as a permanent restorative material if there is no high occlusal stresses [9].

A shift towards nano-technology, which defines using materials of size ranging from 1 to $100 \mathrm{~nm}$, allowed for improved mechanical properties [11]. Therefore, another development related to changes in GICs based on nano-fillers is glass carbomer (GCP) (GCP Dental, Ridderkerk; The Netherlands). There is a common belief that the material transforms into a fluorapatite-like structure in time [12]. Depending upon nano-fluoride hydroxyapatite particles, the contact between liquid and powder grains increases. Thus, mechanical properties of GCP is enhanced [9]. Furthermore, a strong light source is recommended to cure GCP [9].

As a relatively new restorative material, Cention N alkasite (Ivoclar, Vivadent, Schaan; Liechtenstein) has been introduced into a sub-group of composite resins. Cention $\mathrm{N}$ is a self-curing powder/liquid restorative material, with optional additional light-curing, which is capable of releasing acid-neutralizing ions. It is urethane dimethacrylate (UDMA)-based, tooth-colored filling material, with high flexural strength and low elastic modulus. It can be used with or without adhesive application, and self-adhesion to dentin and enamel is anticipated. With regards to the patented ingredient, called 'isofiller', polymerization shrinkage decreases, resulting in reduced microleakage [2]. Moreover, it was shown that clinical performance of Cention $\mathrm{N}$ is quite satisfying. In a study evaluating failure rate of Cention $\mathrm{N}$ restoration in 6 month, the material was observed to have effective marginal integrity as Tetric N Ceram (Ivoclar, Vivadent; Schaan, Liechtenstein) but with lesser surface characteristics [13].

Since long-term clinical studies in the literature are lacking, it is quite important to evaluate Cention N. Even though there are few studies on this subject, self-adhesive restorative materials have not yet been fully evaluated.

\section{OBJECTIVES}

The objectives of the current study were to investigate the microleakage of 3 different type, commercially available self-adherable ion-releasing materials with regards to pre-treatment procedures, and to compare them with each other to contribute to the literature.

Null hypothesis assessed was that microleakage of all tested restorative materials do not differ significantly from each other.

\section{MATERIAL AND METHODS}

The study started with ethical approval obtained from Pamukkale University Faculty of Medicine Human Ethics committee (number: 60116787-020/47595). All experimental stages of the study were conducted in Pamukkale University Faculty of Dentistry Research Laboratory and Pamukkale University Faculty of Technology Laboratory.

\section{EXPERIMENTAL PROCESS}

Eighty-four freshly extracted (within one month before the experiment) human, non-carious permanent molar teeth, which did not differ greatly in terms of morphology, were chosen. Before cavity preparation, all teeth were cleaned using pumice and prophylaxis rubber. Teeth were controlled with an optical microscopy (Discovery V20, Carl Zeiss; Gottingen, Germany) at $\times 30$ magnification for any hypoplastic defects, caries, restorations, or cracks. Specimens with wear, dentin sclerosis, or discoloration were excluded from the study. Soft tissue remnants and dental plaque on the teeth were cleaned with a periodontal curette. The teeth were disinfected with $0.5 \%$ chloramine T solution (Fisher Scien- 
TABLE 1. Self-adhesive materials used in each group, their composition and application procedures

\begin{tabular}{|c|c|c|c|}
\hline Groups ${ }^{\mathrm{a}}$ & $\begin{array}{l}\text { Material/ manufacturer/ } \\
\text { Batch number }\end{array}$ & Material composition & Application procedure \\
\hline $\begin{array}{l}\text { Hybrid glass } \\
\text { ionomer }\end{array}$ & $\begin{array}{l}\text { EQUIA Forte/GC } \\
\text { Tokyo, Japan/ } \\
1804061\end{array}$ & $\begin{array}{l}\text { Liquid: Polyacrylic acid, distilled water, } \\
\text { polybasic carboxylic acid. } \\
\text { Powder: Fluoro-alumino-silicate glass, } \\
\text { polyacrylic acid powder, pigment, } \\
\text { methyl methacrylate, colloidal } \\
\text { silica, camphorquinone, urethane } \\
\text { methacrylate, phosphoric ester } \\
\text { monomer. }\end{array}$ & $\begin{array}{l}\text { Activate the capsule and mix in a high-frequency mixer. } \\
\text { Apply EQUIA Forte directly into the cavity preparation after } \\
\text { mixing for } 10 \text { s using a mixing device. } \\
\text { Remove excess material. }\end{array}$ \\
\hline Coating & $\begin{array}{l}\text { EQUIA Forte Coat/ } \\
\text { GC Europe, } \\
\text { Leuven, Belgium/0086 }\end{array}$ & $\begin{array}{l}\text { Methylmethacrylate, colloidal silica, } \\
\text { camphorquinone. }\end{array}$ & $\begin{array}{l}\text { Apply EQUIA Forte Coat and additional light for } 20 \text { s using } \\
\text { a LED lamp at a distance of } 1 \mathrm{~mm}\left(1,200 \mathrm{~mW} / \mathrm{cm}^{2} \text {, }\right. \\
\text { standard power curing mode of VALO }{ }^{\mathrm{mm}} \text { Cordless, Ultradent, } \\
\text { South Jordan, UT } 84095, \text { USA) perpendicularly } \\
\text { to the material surfaces. }\end{array}$ \\
\hline Alkasite & $\begin{array}{l}\text { Cention N/ Ivoclar Vivadent } \\
\text { AG, Bendererstrasse, } \\
\text { Schaan, Liechtenstein/ } \\
\text { W93722 }\end{array}$ & $\begin{array}{c}\text { Filler: Barium aluminum silicate glass, } \\
\text { ytterbium trifluoride, isofiller (Tetric } \\
\text { N-Ceram technology), calcium barium } \\
\text { aluminum fluorosilicate glass, calcium } \\
\text { fluoro silicate glass. } \\
\text { Liquid: UDMA, DCP, Tetramethyl- } \\
\text { xylylen-diurethane dimethacrylate, } \\
\text { PEG-400 DMA. }\end{array}$ & $\begin{array}{l}\text { Dispense powder and liquid next to each other on a mixing } \\
\text { pad. Mix the first portion of powder with the entire liquid } \\
\text { dispensed. Once the components have been thoroughly } \\
\text { mixed, add the remaining powder and mix again, until } \\
\text { a homogeneous consistency is achieved (45-60 s). } \\
\text { The working time is } 3 \text { min from the start of mixing (when } \\
\text { no light curing). Apply additional polymerized light for } 20 \mathrm{~s} \text {, } \\
\text { using a LED lamp at a distance of } 1 \mathrm{~mm} \\
\text { (1,200 } \mathrm{mW} / \mathrm{cm}^{2} \text {, standard power curing mode of VAL2 } 0^{\mathrm{TM}} \\
\text { Cordless, Ultradent, South Jordan, UT 84095, USA). }\end{array}$ \\
\hline Glass carbomer & $\begin{array}{l}\text { GCP Glass Fill/ } \\
\text { GCP Dental, Vianen, } \\
\text { The Netherlands/7171290 }\end{array}$ & $\begin{array}{c}\text { Powder: Fluoroaluminosilicate glass, } \\
\text { apatite. } \\
\text { Liquid: Polyacids. }\end{array}$ & $\begin{array}{l}\text { Activate the capsule and mix in a high-frequency mixer } \\
\text { (GCP CarboMix, GCP Dental) for } 15 \mathrm{~s} \text {. }\end{array}$ \\
\hline Coating & $\begin{array}{c}\text { GCP Gloss/ } \\
\text { GCP Dental, Vianen, } \\
\text { The Netherlands/ } 71808616\end{array}$ & Modified polysiloxanes. & $\begin{array}{l}\text { Coat the surfaces with GCP Gloss and light-cure for } 60 \mathrm{~s} \text {, } \\
\text { with a high output light device (GCP (arboLED, GCP Dental). }\end{array}$ \\
\hline $\begin{array}{l}\text { Nanohybrid } \\
\text { composite resin }\end{array}$ & $\begin{array}{l}\text { Grandio So/VOCO } \\
\text { GmbH, Cuxhaven, } \\
\text { Germany/1806497 }\end{array}$ & $\begin{array}{c}\text { Glass ceramic filler (particle size } 1 \mu \mathrm{m} \text { ), } \\
\text { silicon dioxide nano-particles (range, } \\
20-40 \mathrm{~nm} \text { ), Bis-GMA, Bis-EMA, } \\
\text { TEGDMA, initiators, inorganic pigments, } \\
\text { BHT. }\end{array}$ & $\begin{array}{l}\text { Apply the composite resin material in one increment and } \\
\text { light cure for } 40 \mathrm{~s} \text {, using a LED lamp at a distance of } 1 \mathrm{~mm} \\
\left(1200 \mathrm{~mW} / \mathrm{cm}^{2} \text {, standard power curing mode of VALO }\right. \\
\text { Cordless, Ultradent, South Jordan, UT 84095, USA). }\end{array}$ \\
\hline
\end{tabular}

Bis-GMA - bisphenol-A-diglycidyl methacrylate, TEGDMA - triethyleneglycol dimethacrylate, S-PRG filler - surface pre-reacted glass-ionomer filler, UDMA - urethane dimethacrylate, DCP - tricyclodecan-dimethanol dimethacrylate, PEG-400 DMA - polyethylene glycol 400 dimethacrylate, DMA - dimethacrylate, BisEMA - ethoxylated bisphenol-A dimethacrylate, BHT-butylhydroxytoluene

${ }^{a}$ All of the above materials are from shade $A 2$.

tific; Pittsburg, PA, USA) at $4^{\circ} \mathrm{C}$ for 1 week, and kept in distilled water at $4^{\circ} \mathrm{C}$ until use.

\section{CAVITY PREPARATION}

Eighty-four box-shaped class $\mathrm{V}$ cavities (5 $\mathrm{mm}$ width and $2.5 \mathrm{~mm}$ depth) were prepared. Gingival cavity edge was finished $1 \mathrm{~mm}$ below the enamel-cement border. Cavity edges were not beveled. Cavity preparations were completed by using a flat-end diamond fissure bur No. 836/ 010 (Maxima Diamond, Henry Schein; Port Washington, NY, USA) in a high-speed aerator handpiece under water cooling. The bur was replaced after every five preparations. For dimension and depth standardization, a periodontal probe (PCP-UNC $15 \mathrm{Hu}$-Friedy; Leimen, Germany) was applied. All preparations were completed by one clinician for standardization.

Afterwards, prepared cavities were randomly assigned into 7 experimental groups with regards to applied self-adherable ion-releasing material and pre-treatment procedures $(n=12)$. Group 1: HGI (EQUIA Forte Fil, GC Corp., Tokyo, Japan) without pre-treatment; Group 2: HGI (EQUIA Forte Fil, GC Corp., Tokyo, Japan) with pre-treatment (Dentin Conditioner, GC Corp.; Tokyo, Japan); Group 3: GCP (GCP Fil, GCP Dental; Vianen, The Netherlands) without pre-treatment; Group 4: GCP (GCP Fil, GCP Dental; Vianen, The Netherlands) with pre-treatment (Dentin Conditioner, GC Corp.; Tokyo, Japan); Group 5: Alkasite (Cention N, Ivoclar Vivadent; India) without adhesive resin; Group 6: Alkasite (Cention $\mathrm{N}$, Ivoclar Vivadent; India) with adhesive resin (Clearfil 
SE Bond, Kuraray Noritake Dental; Okayama, Japan); Group 7: Nano-hybrid composite resin (Grandio SO, Voco; Cuxhaven, Germany) with adhesive resin (Clearfil SE Bond Kuraray, Noritake Dental; Okayama, Japan).

Materials used in this study and their compositions are presented in Table 1. Cavities were restored according to manufacturers' instructions.

Polishing procedures were started $8 \mathrm{~min}$ after for HGI, and 4 min after for GCP and Cention N. Each specimen was polished with aluminum-oxide multi-step polishing discs (Optidisc, Kerr; CA, USA) for $15 \mathrm{~s}$ for each disc (extracoarse, coarse, fine, and extra-fine). Then, a two-step diamond impregnated rubber polishers (KerrHawe HiLuster Plus Kerr; CA, USA) was applied for $15 \mathrm{~s}$ for each bur (fine and extra-fine). Polishing procedures were held by using a low-speed hand piece under dry conditions.

\section{THERMAL CYCLING AND MICROLEAKAGE EVALUATION}

All of the specimens were subjected to thermal cycling in a thermocycling device (MTE 101 thermocycling machine, Esetron; Ankara, Turkey) alternating between $5 \pm 2^{\circ} \mathrm{C}$ to $55 \pm 2^{\circ} \mathrm{C}$ for 5,000 cycles, with an exposure time of $30 \mathrm{~s}$ and a dwelling time of $15 \mathrm{~s}$. Afterwards, root apices were sealed with wax (Modelling Wax, Dentsplay; Turkey), and the teeth were covered with two coats of nail varnish to within $1 \mathrm{~mm}$ beyond margins of the restorations.
The teeth were immersed in $1 \%$ methylene blue dye ( $\mathrm{pH}=7$ ) solution for $24 \mathrm{~h}$, except for the roots. Then, they were washed for 1 min under running tap water, and dried.

A precise diamond saw was used to cut the teeth longitudinally through the center of restorations under continuous water irrigation (Micracut, Metkon, Bursa; Turkey; rotational speed range, 0-300 rpm). Three sections were obtained from each tooth. Sections' surface was examined under stereomicroscope (Discovery V20, Carl Zeiss; Gottingen, Germany) at $\times 40$ magnification. To prevent bias, the samples were numbered and mixed for blending. Two clinicians scored depth of dye penetration separately at enamel and dentin margins, according to microleakage scores: 0 - no dye penetration; 1 - dye penetration up to half of the wall; 2 - dye penetration for more than half of the wall; 3 - dye penetration of the entire wall, including the axial wall [14].

\section{STATISTICAL ANALYSIS}

The sample size of each group was determined using a power analysis ( $G$ Power 3.1.9.2 software), with statistical difference of $p=0.05$, and effect size of 0.3 at $95 \%$ power.

Data were analyzed using SPSS for Windows software (version 22.0; SPSS Inc.; Chicago, IL, USA). ShapiroWilk test was applied to determine normality of distribution. Kruskal-Wallis test and Mann-Whitney $U$-test

Enamel micro-leakage scores

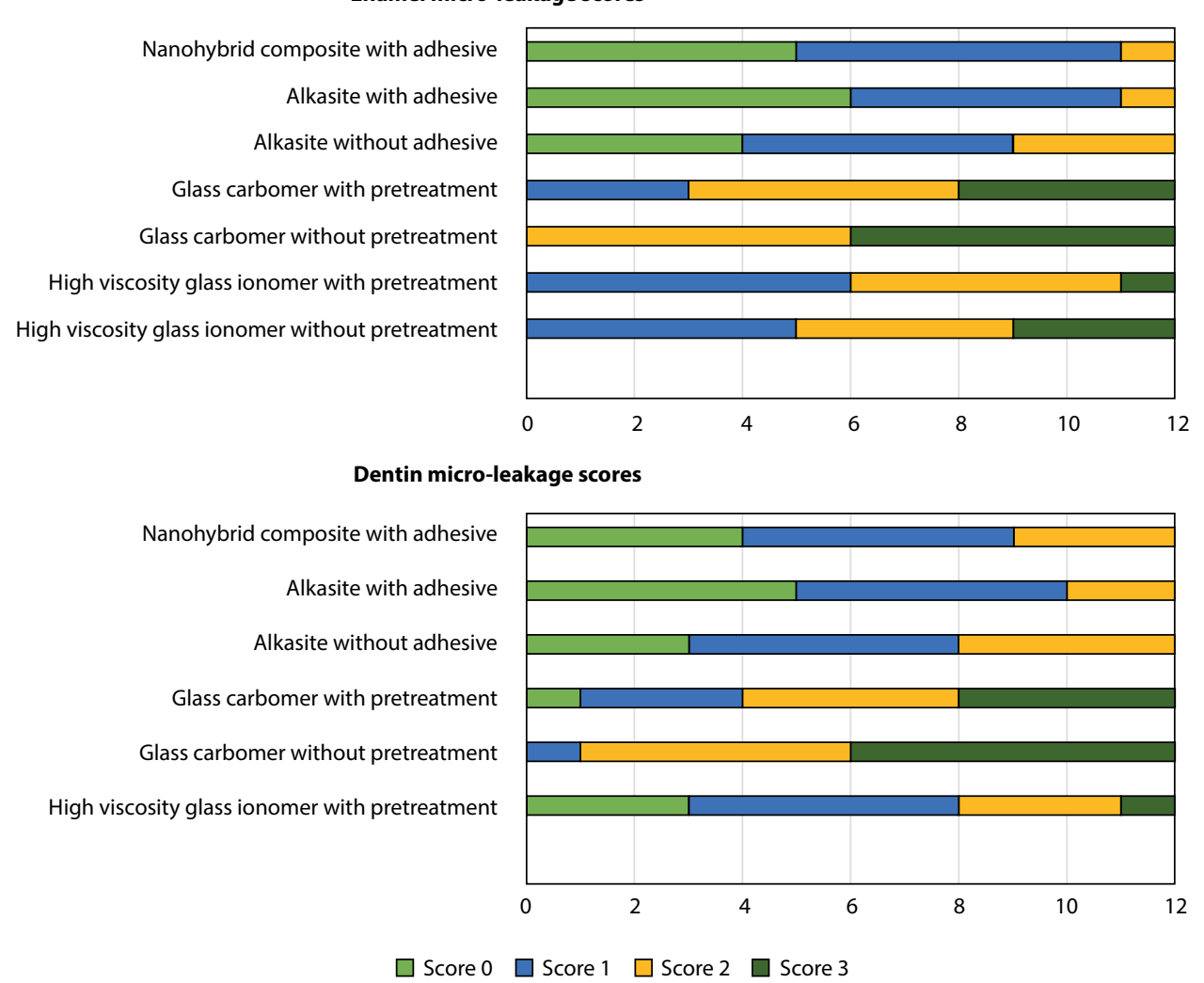

FIGURE 1. Scores of dye penetration on enamel and dentin margins for each group 
TABLE 2. Mean and standard deviation (SD) values of microleakage scores obtained from experimental groups at occlusal and gingival edges, and their statistical comparisons $(p<0.05)$

\begin{tabular}{|c|c|c|c|}
\hline Experimental groups & $n$ & Mean \pm SD & Median (min.-max.) \\
\hline \multicolumn{4}{|l|}{ Enamel results } \\
\hline High viscosity glass ionomer without pre-treatment (group 1) & 12 & $1.83 \pm 0.24^{\mathrm{a}}$ & $2.00(1.00-3.00)$ \\
\hline High viscosity glass ionomer with pre-treatment (group 2) & 12 & $1.58 \pm 0.19^{b}$ & $1.50(1.00-3.00)$ \\
\hline Glass carbomer without pre-treatment (group 3) & 12 & $2.50 \pm 015^{c}$ & $2.50(2.00-3.00)$ \\
\hline Glass carbomer with pre-treatment (group 4) & 12 & $1.83 \pm 0.27^{a}$ & $2.00(0.00-3.00)$ \\
\hline Alkasite without adhesive (group 5) & 12 & $1.17 \pm 0.27^{d}$ & $1.00(0.00-3.00)$ \\
\hline Alkasite with adhesive (group 6) & 12 & $0.58 \pm 0.19^{e}$ & $0.50(0.00-2.00)$ \\
\hline Nano-hybrid composite resin with adhesive (group 7) & 12 & $0.67 \pm 0.19^{e}$ & $1.00(0.00-2.00)$ \\
\hline Test statistic & \multicolumn{3}{|c|}{35.599} \\
\hline$p$-value* & \multicolumn{3}{|c|}{0.001} \\
\hline \multicolumn{4}{|l|}{ Dentin results } \\
\hline High viscosity glass ionomer without pre-treatment (group 1) & 12 & $1.58 \pm 0.25^{\mathrm{a}}$ & $1.50(0.00-3.00)$ \\
\hline High viscosity glass ionomer with pre-treatment (group 2) & 12 & $1.17 \pm 0.27^{b}$ & $1.00(0.00-3.00)$ \\
\hline Glass carbomer without pre-treatment (group 3) & 12 & $2.41 \pm 0.19 c$ & $2.50(1.00-3.00)$ \\
\hline Glass carbomer with pre-treatment (group 4) & 12 & $1.91 \pm 0.29^{\mathrm{a}}$ & $2.00(0.00-3.00)$ \\
\hline Alkasite without adhesive (group 5) & 12 & $1.08 \pm 0.23^{b}$ & $1.00(0.00-2.00)$ \\
\hline Alkasite with adhesive (group 6) & 12 & $0.75 \pm 0.21^{b}$ & $1.00(0.00-2.00)$ \\
\hline Nano-hybrid composite resin with adhesive (group 7) & 12 & $0.91 \pm 0.22^{b}$ & $1.00(0.00-2.00)$ \\
\hline Test statistic & \multicolumn{3}{|c|}{25.894} \\
\hline$p$-value ${ }^{*}$ & \multicolumn{3}{|c|}{0.001} \\
\hline
\end{tabular}

$S D$ - standard deviation. *Different letters in the same column represent statistically significant difference between the groups.

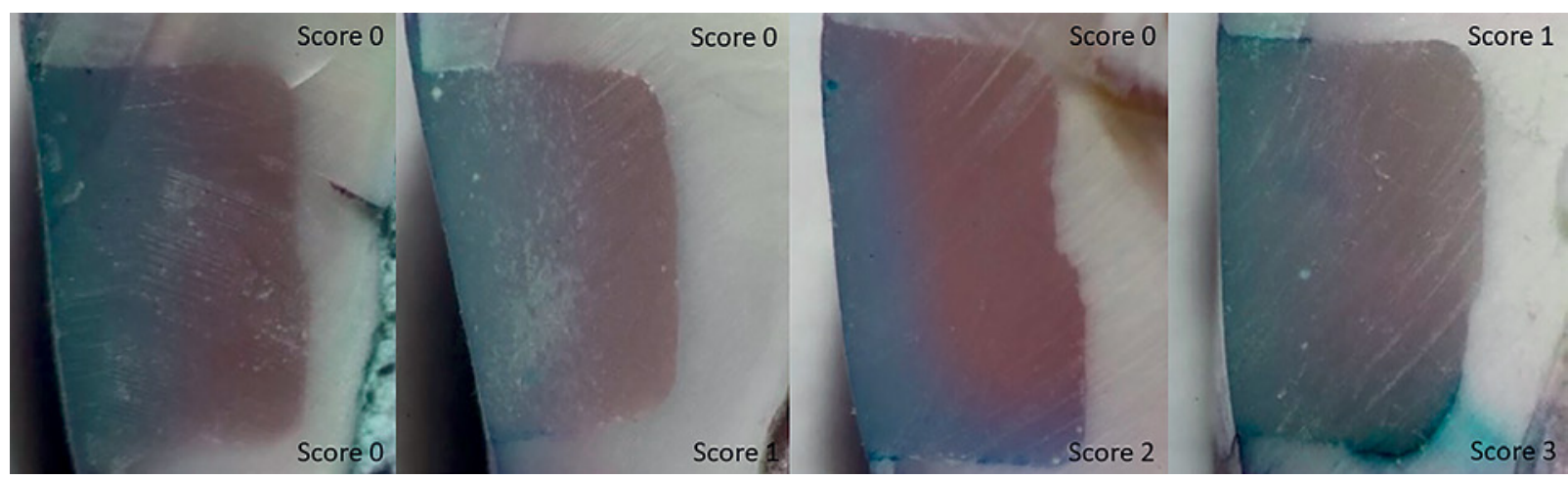

FIGURE 2. Photographs obtained from different groups representing each microleakage score $(0,1,2$, and 3$)$

with Bonferroni correction was used to examine statistical differences among the groups.

\section{RESULTS}

The mean and standard deviation values of microleakage scores obtained from groups at enamel and dentin margins (Figure 1) and multiple comparisons are presented in Table $2(p<0.05)$. Photographs taken from different groups representing each microleakage score $(0,1$, 2 , and 3 ) are shown in Figure 2. There were statistically significant differences among the groups in microleakage value both at enamel and dentin margins (KruskalWallis test, $p<0.05)$. When leakage values obtained from enamel margins were analyzed, microleakage values increased in Cention $\mathrm{N}$ with adhesive $=$ nanohybrid composite resin with adhesive $<$ Cention $N$ without adhesive $<$ HGI with pre-treatment $<$ HGI without pretreatment $=$ GCP with pre-treatment $<$ GCP without pre-treatment (Table 2).

When leakage values obtained from dentin margins were analyzed, microleakage values increased in Cen- 
tion $\mathrm{N}$ with adhesive $=$ nano-hybrid composite resin with adhesive $=$ Cention $\mathrm{N}$ without adhesive $=\mathrm{HGI}$ with pre-treatment $<$ HGI without pre-treatment $=$ GCP with pre-treatment $<$ GCP without pre-treatment (Table 2).

\section{DISCUSSION}

In the present study, a comparative investigation of various ion-releasing self-adhesive restorative materials with regards to microleakage were examined. The null hypothesis that microleakage of all tested restorative materials do not differ significantly from each other was rejected, since the results showed that microleakage properties of restorative materials were material-dependent and may change due to pre-treatment methods.

Microleakage can be defined as a transition of bacteria, fluids, or molecules in microcaps (range, 6-10 $\mu \mathrm{m}$ ) between the cavity wall and a restorative material that leads to post-operative sensitivity, pulpal inflammation, and secondary caries [15-17].

In this present study, class $\mathrm{V}$ cavities were tested because of weak bonding in this area, which is more prone to microleakage [18]. To discard bias, identically similar teeth were selected, and cavity standardization was performed by one researcher.

Thermal and mechanical stresses affect the lifetime of restorations by creating marginal gaps. In the present study, to simulate the variation of oral conditions, thermocycling was performed. Although radioactive isotopes, scanning electron microscope, neutron activation analysis, and confocal laser scanning microscope can all be used as test methods to evaluate microleakage, dye penetration is still the most popular technique [3, 18]. Hence, a dye material was used for detecting microleakage scores since the diameter of dye molecule $(0.80 \mathrm{~nm})$ is smaller than dentinal tubule (range, 1-4 $\mu \mathrm{m}$ ) [16-19].

The selection of composite resin is crucial for clinical success, when restoring in posterior loadbearing areas. Composite resins placed in conjunction with certain dental adhesives are believed to lose their sealing ability over time, thus permitting microleakage. The Academy of Operative Dentistry - European section recommends the use of micro-hybrid or nano-hybrid composite resins, with a minimum of $60 \%$ filler load by volume. Therefore, in this study, $89 \%$ of filled nano-hybrid composite resin was selected as a control group [20].

Dentin interface has challenging properties for bonding, with higher organic content, tubular structure, fluid pressure, and low surface energy, when compared to enamel. Moreover, dentin contains parallel tubules, which run towards the pulp [18]. In line with structural properties, statistically significantly higher microleakage results were obtained in dentin.

In the current study, comparatively lower microleakage scores of Cention N over HGI or GCP was observed. This lower scores in Cention $\mathrm{N}$ could be related to Ivo- cerin-based, special patented filler (isofiller) that acts as a shrinkage stress reliever. Additionally, Cention $\mathrm{N}$ has low elastic modulus (10 GPa) reducing polymerization shrinkage, thus microleakage $[19,21]$. Glass fillers used in composite resins have generally higher modulus of elasticity (71 GPa) [19]. However in this study, as a control group, nano-hybrid composite resin (Grandio SO), which demonstrates elasticity (16.65 GPa) closest to dentine was selected [22]. This may also be the reason for comparable microleakage scores for Cention $\mathrm{N}$ and a control group.

Similar to present study, George et al. [21] showed Cention $\mathrm{N}$ to have better sealing ability, when compared to GIC and composite resin restorations. Sahu et al. [19] used rhodamine dye and confocal laser scanning microscope technique, and showed less microleakage in Cention $\mathrm{N}$ when compared to a bulk-filled composite resin (Tetric N-Ceram Bulk Fill, Ivoclar Vivadent; India). Moreover, another study by Mazumdar et al. [1] reported lower microleakage scores in Cention $\mathrm{N}$ compared to silver amalgam or type II GIC. Moreover, Kaur et al. [23] revealed that Cention $\mathrm{N}$ showed less microleakage scores than conventional GIC. Samanta et al. [24] also found lesser microleakage scores in Cention $\mathrm{N}$ compared to flowable composite resin. On the contrary, Bharath et al. [15] observed that HGI (i.e., EQUIA Forte) have smaller microleakage scores than Cention N. The researchers related their results to a single component structure of HGI, while Cention $\mathrm{N}$ required mixing.

Cention $\mathrm{N}$ can be used with or without adhesive. This material does not show a micro-mechanical bond comparable to glass ionomer restoratives, which is why the manufacturer recommends that if it is used without adhesive conventional tooth preparation, retentive features should be applied [25]. In line with the manufacturer's recommendations, in this present study, Cention $\mathrm{N}$ with adhesive presented the least microleakage scores, which were statistically similar to the control group in both enamel and dentin.

In the present study, two-step Clearfil SE Bond (Kuraray Noritake Dental; Okayama, Japan) was selected since it is a gold standard of self-etch adhesives when bonding on dentin [26]. The reason for lower microleakage scores within the groups with adhesive can be attributed to the bonding between hydrophilic tooth and hydrophobic restoration. Therefore, the created seal helped to prevent microleakage [27].

Sahu et al. [19] revealed promising lesser microleakage scores, especially when using Cention $\mathrm{N}$ with an adhesive. In a study, Kini et al. [27] reported Cention $\mathrm{N}$ with adhesive resulting in least microleakage among Cention $\mathrm{N}$ without adhesive, type IX glass ionomer cement (Fuji, GC; Japan) and posterior composite (3M ESPE; St. Paul, MN, USA). Similarly, Meshram et al. found lesser scores in Cention $\mathrm{N}$ combined with adhesive in enamel when compared to Cention $\mathrm{N}$ without adhesive or flowable composite resin (Tetric-N-Flow, Ivoclar Vivadent; India) [17]. Contrary to the present study, George et al. [21] re- 
vealed that Cention $\mathrm{N}$ without adhesive showed lesser microleakage than Cention $\mathrm{N}$ with adhesive. Different results can be related to changes in dentin structure, size, or location of dentinal tubules within the tooth, which may have an effect on properties of materials.

GICs bond by micromechanical interlocking and chemical bonding to hydroxyapatite in tooth structure. GICs mechanism of adhering tooth can be considered of as a 'mild self-etch approach'. However, GICs adhere better when combined with etch-and-rinse step [11]. Polyacrylic acid is commonly used as a conditioner both in enamel and dentine pre-treatments, to remove the smear layer [28]. It results in partial demineralization and increased surface area. Therefore, microporosities allow for micromechanical retention [29]. Omitting this polyacrylic acid step saves time and reduce technical sensitivity [11]. However in this study, in both enamel and dentin, the microleakage scores in HGI without pre-treatment were considered statistically significantly higher than HGI with pre-treatment, and comparable results were obtained in GCP with pre-treatment. According to the literature, higher microleakage results might be responsible, and are possibly related to the lack of additional conditioning steps [11]. Also, HGI with pre-treatment showed comparable results with the control group in dentin $(p>0.05)$, while higher microleakage scores were noted in enamel $(p<0.05)$. Thus, clinicians should consider to use polyacrylic acid conditioning, especially when adhesion forces are more crucial, like in this study, in cervical lesions. Another reason for microleakage pattern in HGI used in the present study was most likely due to high viscosity, which may be responsible for inadequate wetting of the tooth surface.

GCP material sets through an acid-base reaction, being a kind of GIC. Water plays a crucial role when bonding GICs to dental substrates, and acts as a medium to provide ion exchange [29]. Moreover, the manufacturer recommends using heat to speed up the setting time of GCP restorative material [30]. Here, the authors found comparatively lesser microleakage scores of Cention $\mathrm{N}$ and HGI over GCP. The reason for the highest microleakage scores of GCP may be due to high intensity light curing that may resulted in water evaporation. Ülker et al. [3] evaluated microleakage of resin-modified GIC, self-adhesive composite resin GCP, and found more microleakage scores in GCP. This might be explained by a weak adhesion between tooth and GCP. Shebl et al. [31] showed lower bond strength results of GCP when compared to conventional GIC. Also, Munervveroglu et al. [32] observed lesser microleakage scores in high viscosity GIC (EQUIA Fil, C Corp.; Tokyo, Japan) when compared to GCP. Moreover, Cehreli et al. [33] conducted a study evaluating primary molars, and found higher microleakage scores in GCP, which presented internal and surface's cracks when compared to GIC.

It has been suggested that polyacrylic acid increase adhesion between GCP and tooth substrate, just like GICs
[29]. Therefore, in the present study, to enhance bond strength and lessen microleakage scores of GCP, polyacrylic acid conditioning on enamel and dentin surfaces was performed. GCP with pre-treatment in both enamel and dentin demonstrated statistically significantly lesser microleakage scores than GCP without pre-treatment. In line with this study, Ayar et al. [29] reported statistically significantly lesser bond strengths to enamel and dentin, when using GCP without any surface pre-treatment.

Limitations of the present study included intraoral conditions, which could affect the microleakage. Moreover, in this study, extracted teeth were evaluated, and moisture arising from the pulp chamber was reduced. Indeed, clinical evaluations provide better knowledge about the performance of materials for preliminary studies performed in vitro [31]. Therefore, both in vitro and in vivo future studies are recommended, investigating self-adhesive materials and their sealing ability.

\section{CONCLUSIONS}

None of the tested materials were free from microleakage. In this present study, the authors revealed that Cention $\mathrm{N}$ is a promising alternative restorative material with lesser microleakage over HIC and GCP, and comparable properties with nano-hybrid composite resin. Particularly in enamel, Cention $\mathrm{N}$ combined with an adhesive, is preferred. Clinicians also should keep in mind that conditioning with polyacrylic acid improves sealing ability and decreases microleakage scores of HGI and GCP restorative materials. Therefore, additional pre-treatment is recommended especially in stress bearing areas.

\section{CONFLICT OF INTEREST}

The authors declare no potential conflicts of interest with respect to the research, authorship, and/or publication of this article.

\section{References}

1. Mazumdar P, Das A, Das UK. Comparative evaluation of microleakage of three different direct restorative materials (silver amalgam, glass ionomer cement, cention N), in Class II restorations using stereomicroscope: an in vitro study. Indian J Dent Res 2019; 30: 277-281.

2. Bore Gowda V, Sreenivasa Murthy BV, Hegde S, et al. Evaluation of gingival microleakage in class II composite restorations with different lining techniques: an in vitro study. Scientifica (Cairo) 2015; 2015: 896507.

3. Ülker HE, Günaydın N, Erkan AI, et al. Microleakage of different self-adhering materials. MCMR 2017; 1: 49-54.

4. Browning W. The benefits of glass ionomer self-adhesive materials in restorative dentistry. Compend Contin Educ Dent 2006; 27 308-314; quiz 315-316.

5. Maas MS, Alania Y, Camargo NL, et al. Trends in restorative composites research: what is in the future? Braz Oral Res 2017; 31: e55.

6. Najeeb S, Khurshid Z, Zafar MS, et al. Modifications in glass ionomer cements: nano-sized fillers and bioactive nanoceramics. Int J Mol Sci 2016; 17: 1134 
7. Wilson $\mathrm{AD}$, Kent BE. A new translucent cement for dentistry The glass ionomer cement. Br Dent J 1972; 132: 133-135.

8. Brzović-Rajić V, Miletić I, Gurgan S, et al. Fluoride release from glass ionomer with nano filled coat and varnish. Acta Stomatol Croat 2018; 52: 307-313.

9. Buldur M, Karaarslan ES. Microhardness of glass carbomer and high-viscous glass Ionomer cement in different thickness and thermo-light curing durations after thermocycling aging. BMC Oral Health 2019; 19: 273.

10. Balkaya H, Arslan S, Pala K. A randomized, prospective clinical study evaluating effectiveness of a bulk-fill composite resin, a conventional composite resin and a reinforced glass ionomer in class II cavities: one-year results. J Appl Oral Sci 2019; 27: e20180678.

11. Coutinho E, Cardoso MV, De Munck J, et al. Bonding effectiveness and interfacial characterization of a nano-filled resin-modified glass-ionomer. Dent Mater 2009; 25: 1347-1357.

12. Van Duinen RN, Davidson CL, De Gee AJ, et al. In situ transformation of glass-ionomer into an enamel-like material. Am J Dent 2004; 17: 223-227.

13. Dodiya PD, Parekh V, Gupta MS, et al. Clinical evaluation of Cention-N and nano hybrid composite resin as a restoration of non-carious cervical lesion. J Dent Spec 2019; 7: 3-5.

14. Manhart J, Chen HY, Mehl A, Weber K, Hickel R. Marginal quality and microleakage of adhesive class V restorations. J Dent 2001; 29: 123-130.

15. Bharath MJ, Sahadev CK, Sandeep R, et al. Comparative evaluation of microleakage in alkasite and glass-hybrid restorative system: an in-vitro. Int J Res 2019; 7: 199-205.

16. Sujith R, Yadav TG, Pitalia D, et al. Comparative evaluation of mechanical and microleakage properties of Cention-N, composite, and glass ionomer cement restorative materials. J Contemp Dent Pract 2020; 21: 691-695.

17. Meshram P, Meshram V, Palve D, et al. Comparative evaluation of microleakage around Class $\mathrm{V}$ cavities restored with alkasite restorative material with and without bonding agent and flowable composite resin: An in vitro study. Indian J Dent Res 2019; 30: 403-407.

18. Aakriti RJ, Bhushan J, Bhagat P. To evaluate and compare microleakage in teeth restored with conventional glass ionomer cement and two newer restorative materials EQUIA Forte and Cention $\mathrm{N}$ using stereomicroscope. J Adv Med Dent Scie Res 2020; 8: 163-167.

19. Sahu S, Ali N, Misuriya A, et al. Comparative evaluation of microleakage in class I cavities restored with amalgam, bulk-fill composite and Cention-N - an in vitro confocal laser scanning microscope study. Int J Oral Care Res 2018; 6: 81-85.

20. Kutuk ZB, Ozturk C, Cakir F, et al. Mechanical performance of a newly developed glass hybrid restorative in the restoration of large MO Class 2 cavities. Niger J Clin Pract 2019; 22: 833-841.

21. George P, Bhandary S. A comparative microleakage analysis of a newer restorative material - an exvivo study. IOSR J Dent Med Sci 2018; 17: 56-60.

22. Grandio SO. Universal nanohybrid restorative material [Internet]. Available from: https://www.voco.dental/cn/portaldata/1/resources/ products/folders/gb/grandioso_fol_gb.pdf (Accessed: 24.01.2020).

23. Kaur M, Mann NS, Jhamb A, et al. A comparative evaluation of compressive strength of Cention $\mathrm{N}$ with glass ionomer cement: an in-vitro study. Int J Appl Dent Sci 2019; 5: 5-9.

24. Samanta S, Das UK, Mitra A. Comparison of microleakage in class $\mathrm{V}$ cavity restored with flowable composite resin, glass ionomer cement and Cention N. IJIR 2017; 3: 180-183.

25. Mishra A, Singh G, Singh SK, et al. Comparative evaluation of mechanical properties of Cention $\mathrm{N}$ with conventionally used restorative materials - an in vitro study. Int J Prosthodont Restor Dent 2018; 8: 120-124.

26. Kermanshah H, Khorsandian H. Comparison of microleakage of Scotchbond ${ }^{\mathrm{TM}}$ Universal Adhesive with methacrylate resin in Class V restorations by two methods: swept source optical coherence tomography and dye penetration. Dent Res J (Isfahan) 2017; 14: 272-281.
27. Kini A, Shetty S, Bhat R, et al. Microleakage evaluation of an alkasite restorative material: an in vitro dye penetration study. J Contemp Dent Pract 2019; 20: 1315-1318.

28. Sauro S, Watson T, Moscardó AP, et al. The effect of dentine pre-treatment using bioglass and/or polyacrylic acid on the interfacial characteristics of resin-modified glass ionomer cements. J Dent 2018; 73: 32-39.

29. Ayar MK, Güven ME. Bond strength of glass carbomer material to enamel and dentin following different surface pretreatments. J Adhes Sci Technol 2017; 4243: 1929-1937.

30. GCP GLASS SEAL [Internet]. Available from: http://www.trycare. co.uk/images/ww/product/Instructions-of-use-seal-UK.pdf (Accessed: 24.01.2020)

31. Shebl EA, Etman WM, Genaid TM, et al. Durability of bond strength of glass-ionomers to enamel. Tanta Dent J 2015; 12: 16-27.

32. Münevveroğlu AP, Ozsoy A, Akgol BB, et al. Microleakage of high viscosity glass-ionomer and glass-carbomer with and without coating before and after hydrothermal aging. Braz Dent Sci 2019; 22: 70-87.

33. Cehreli SB, Tirali RE, Yalcinkaya Z, et al. Microleakage of newly developed glass carbomer cement in primary teeth. Eur J Dent 2013; 7: 15-21. 